\title{
El derecho del patrimonio cultural. Análisis desde la perspectiva de los derechos humanos y su aplicación por el Instituto Nacional de Antropología e Historia (INAH), México
}

Cultural Heritage Rights: An Analysis from the Human Rights Perspective and their Implementation by the Instituto Nacional de Antropología e Historia (INAH, National Institute of Anthropology and History), Mexico

Miguel Ángel Mesinas Nicolás

Museo de las Culturas de Oaxaca (MCO),

Instituto Nacional de Antropología e Historia (INAH), México

migue_mesinas@hotmail.com

\section{Resumen}

Debido al escaso interés tanto de los gobiernos como de especialistas en cultura y de la sociedad misma, el tema sobre el derecho cultural se ha desarrollado con lentitud. En cuanto a sus logros, en su mayor parte se fundamentan en el estudio de los derechos humanos, que ha servido como mecanismo de aproximación y de fuente de fundamentación y anclaje con la sociedad. Este REPORTE explora el derecho del patrimonio cultural como componente primario de la dignidad humana — derecho a la vida, a la vivienda y al trabajo—, así como su proceso de formación vinculado a la categorización de los derechos culturales; analiza, asimismo, sus relaciones con la normatividad en materia de patrimonio cultural existente en México, en particular con la que es competencia del Instituto Nacional de Antropología e Historia (INAH, México). El análisis con que se aborda esta contribución responde a un marco teórico estructurado desde la disciplina de las relaciones internacionales, el cual abre la interacción de los regímenes internacionales de los derechos humanos (RIDH) para una comprensión integral e interdisciplinaria.

\section{Palabras clave}

derecho del patrimonio; derecho cultural; derechos humanos; monumentos; México; derecho internacional 


\section{Abstract}

Due to the lack of interest on the part of the government, cultural specialists and society as a whole, the subject of cultural law has developed slowly. In terms of its achievements, these have largely been based on the study of human rights, which have served as a mechanism for approaching the issue and for grounding it in society. This chronicle explores cultural heritage rights as a primary component of human dignity -along with the right to live, housing and work- and examines the educational process linked to the categorization of cultural rights. It also studies the relationship of cultural heritage rights with Mexico's existing cultural heritage regulations, in particular, those under the jurisdiction of the National Institute of Anthropology and History (INAH, Mexico). This analysis is based on a structured theoretical framework derived from international relations that provides a further understanding of the interaction of different international human rights regimes within a comprehensive and interdisciplinary context.

\section{Key words}

cultural heritage rights; cultural rights; human rights; heritage; monuments; Mexico; international rights.

\section{Introducción}

El derecho cultural entendido como "subsistema jurídico normativo de la actividad cultural" (Ávila 2000:50) se ha diseminado gracias a documentos internacionales emitidos por diversas organizaciones intergubernamentales (OIG), entre los que destacan los de la Organización de las Naciones Unidas (ONU), la Organización de los Estados Americanos (OEA) y la Unión Europea (UE). Como se piensa que los regímenes internacionales de los derechos humanos $^{1}$ (RIDH) emanados de dichos organismos posibilitan la creación de políticas culturales en cuanto que fijan los criterios, las creencias y los conceptos esenciales que fortalecen tanto la protección del patrimonio cultural como las instituciones encargadas de regular dicha materia — como el Instituto Nacional de Antropología e Historia (INAH, México), organismo de máxima competencia en la salvaguardia, protección, investigación, conservación y difusión de monumentos arqueológicos e

\footnotetext{
${ }^{1}$ Una de las definiciones más aceptada del concepto de régimen internacional proviene de Stepehen D. Krasner, el cual lo define como el "tipo de institución internacional conformado por un conjunto de principios, normas, reglas y procedimientos de toma de decisiones adoptados y establecidos por los Estados para regular sus interacciones alrededor de un área temática específica de la esfera internacional" (Anaya 2014:64). La utilización del término regímenes internacionales de los derechos humanos (RIDH), en vez de este otro, en singular: régimen internacional de los derechos humanos, refleja la diversidad tanto de los instrumentos internacionales como de las organizaciones intergubernamentales (OIG) que los componen (Anaya 2014:65). Para observar la catalogación de los regímenes en materia de derechos humanos, véase Anaya 2014.
}

históricos en México-, es posible tener en nuestro país un panorama optimista del patrimonio cultural.

El origen del derecho cultural y el de una de sus ramas: el derecho del patrimonio cultural, se halla en los RIDH: ahí residen los principios, normas y criterios que, ratificados en los tratados de los Estados participantes, plasman su preocupación por la vida cultural de los pueblos. El objeto del presente REPORTE, así, es describir y analizar, desde un marco teórico de las relaciones internacionales, el paradigma transnacional y la teoría de los regímenes internacionales presentes en el derecho del patrimonio cultural, ${ }^{2}$ así como exponer la información que nos acerca a este concepto y la forma en que, por medio del INAH, se armoniza en México.

\section{Antecedentes}

Para iniciar, valga el señalamiento de que un documento fundacional en la defensa de los derechos culturales fue la Declaración Universal de los Derechos Humanos (DUDH), ${ }^{3}$ publicada en 1948, cuyo artículo 27 ya señalaba que "Toda persona tiene derecho a tomar parte libremente en la vida cultural de la comunidad, a gozar de las artes y a participar en el progreso científico y en los beneficios que de él resulten" (ONU 1948:art. 27). Este precepto exige, no obstante, una idea más clara sobre el significado del término vida cultural, que aquí se traza de una manera muy genérica.

Ciertamente, a lo largo de los años los distintos instrumentos jurídicos internacionales han enriquecido dicho concepto mediante un progreso gradual que ha buscado maximizar los bienes del Estado hasta alcanzar la plena efectividad del derecho cultural. Asimismo, antes de que se ratificara la DUDH, en México ya se observaban diversas leyes y sistemas jurídicos nacionales que consideraban la cultura como una garantía: la Constitución Política de los Estados Unidos Mexicanos de 1917, por ejemplo, la establecía como parte del derecho a la libre determi-

\footnotetext{
${ }^{2}$ Las principales características de este paradigma que se destacan para efectos de esta contribución son: por un lado, el mundo está caracterizado, como consecuencia del acelerado desarrollo social, económico, científico-técnico y comunicacional, por el creciente fenómeno de la interdependencia y la cooperación, por lo que las relaciones internacionales responden a un modelo basado más en factores culturales, tecnológicos y económicos que en los estrictamente políticos. De los valores exclusivamente individualistas y nacionales del pasado, se pasa a la afirmación de valores comunes y universales (Arenal 2010:35). Por otro lado, según la perspectiva transnacionalista, los regímenes son acuerdos de gobierno — de gestión, más bien- entre los actores egoístas y calculadores, conscientes del hecho de que la falta de coordinación entre sus políticas sólo les conduce a maximizar los riesgos y minimizar los beneficios. Estos regímenes suministran los criterios y el marco de una actuación que queda, así, legitimada, lo que facilita el comportamiento de los actores (García 2009:149).

${ }^{3}$ Con el propósito de posibilitar una lectura fluida del REPORTE, en ocasiones repetiré en notas de pie el significado de algunas siglas.
} 
nación y autonomía (CC 1917:art. 2). Respecto del patrimonio cultural, destaca la controversia constitucional que el 15 de octubre de 1932 presentó la federación contra el estado de Oaxaca por la expedición de la Ley de Dominio y Jurisdicción de Monumentos Arqueológicos del Estado (cfr. Anon 1932:162-165), que la Corte de Justicia resolvió a favor de la primera para que el segundo se consolidara como el organismo competente en materia de posesión de los bienes arqueológicos. Esto representó un paso fundamental para que dos años después se emitiera la Ley sobre Protección y Conservación de Monumentos Arqueológicos e Históricos, Poblaciones Típicas y Lugares de Belleza Natural (CUEUM 1934) y, posteriormente, en 1939, se fundara el Instituto Nacional de Antropología e Historia (INAH), hasta ese momento, la autoridad federal de competencia en materia de protección, salvaguardia y conservación de patrimonio arqueológico e histórico en nuestro país (González 1998:23).

En otras palabras, este trayecto histórico del gobierno mexicano demuestra que en nuestro país se previó desde épocas muy tempranas del siglo xx la protección tanto de la cultura como del patrimonio cultural, es decir, de aquello que la DUDH (1948:art 27) reafirmaría después en una escala internacional, al reconocer que la vida cultural de los pueblos constituye un derecho humano fundamental.

También en el ámbito continental hubo acciones adelantadas en este sentido: en 1948, en el seno de la OEA, se adoptó la Declaración Americana de Derechos y Deberes del Hombre (DADDH) (OEA 1948:art. XIII), que estableció que

Toda persona tiene el derecho de participar en la vida cultural de la comunidad, gozar de las artes y disfrutar de los beneficios que resulten de los progresos intelectuales y especialmente de los descubrimientos científicos. Tiene asimismo, derecho a la protección de los intereses morales y materiales que le corresponda por razón de los inventos, obras literarias, científicas o artísticas de que sea autor.

Como se aprecia tanto en esta enunciación como en la derivada de la DUDH, arriba mencionada, y no obstante que la relevancia de ambas radica en el establecimiento de la vida cultural como parte de una área temática dentro de la agenda de interés de las OIG, el concepto del derecho de la cultura se asume como amplio y ambiguo. Indiscutiblemente, esta inclusión en el campo jurídico hizo del tema de la vida cultural un asunto global y, por ende, sensibilizó a los regímenes internacionales para que, a su vez, favorecieran la generación de estrategias y acuerdos globales que condicionaran en el comportamiento de los Estados en beneficio de este sector específico.

Casi 20 años después, en 1966, el Pacto Internacional de Derechos Económicos, Sociales y Culturales (PIDESC) adoptado por la Asamblea General de las Naciones Unidas, dio un paso trascendental en el ámbito jurí- dico internacional, al establecer el derecho cultural parte fundamental de los derechos humanos, nominación que, además de exigir a los Estados firmantes tanto responsabilidades como obligaciones jurídicas, dictamina, de acuerdo con su artículo 15, que deben contar con la revisión y la supervisión de diversos mecanismos nacionales e internacionales.

En el pacto los Estados partes reconocen el derecho de toda persona a:

a) Participar en la vida cultural;

b) Gozar de los beneficios del progreso científico y de sus aplicaciones;

c) Beneficiarse de la protección de los intereses morales y materiales que le correspondan por razón de las producciones científicas, literarias o artísticas de que sea autora (PIDESC 1966 :art. 15).

EI PIDESC (OACNUDH 2009) se impuso en la obligación de respetar, proteger, asegurar y promover con cuanta medida fuese posible la garantía de la vida cultural, lo que comportó condicionantes en cuanto a los resultados de su aplicación, "por cuanto su cumplimiento por parte de un Estado determinado se extiende más allá de la aceptación y del subsiguiente reconocimiento" (Niec 2001:294). Es decir, no sólo las políticas públicas empezaron a encaminarse hacia los beneficiarios correspondientes -en este caso, al adoptar medidas para la realización plena de las expresiones culturales de la sociedad - sino también se definió que el Estado mismo fuera el garante de su cumplimiento, con los costos económicos que ello implique. Respecto al contenido normativo del artículo 15, en el 2009, el Comité de Derechos Económicos Sociales y Culturales facultado por el Consejo Económico y Social (Ecosoc, por su acrónimo en inglés) de la ONU, emitió el comentario general núm. 21, el cual propone lo siguiente:

El derecho a participar en la vida cultural puede calificarse de libertad. Para realizarlo, es necesario que, [por un lado], el Estado se abstenga de hacer algo (no tenga injerencia en el ejercicio de las prácticas culturales y en el acceso a los bienes culturales) $[\ldots y$ que, por el otro,...] tome medidas positivas (asegurarse de que existan las condiciones previas para participar en la vida cultural, promoverla y facilitarla y dar acceso a los bienes culturales y preservarlos) (CDESC 2009:3).

Asumir el PIDESC como instrumento fundamental capaz de fijar y sugerir el comportamiento de las autoridades de los países - y como la base para la formulación de conceptos y estructuras legales en sus territorios- ha conducido, con base en la premisa de que la libertad de participar en una vida cultural no puede ejercerse si no existen los criterios de su regulación, a una importante exigencia: que los Estados adopten medidas positivas promoviendo una o varias obligaciones. La actividad estatal, pues, debiese asimismo entenderse en un doble sen- 
tido: tanto de abstención como de responsabilidad. Así, en concurrencia con Víctor Abramovich, María José Añón y Christian Courtis (2003:55), mi idea es que "todos los derechos, Ilámese civiles, políticos, económicos o culturales tienen un costo y prescriben tanto obligaciones negativas como positivas".

La adopción del PIDESC fue de vital importancia en dos rubros: por un lado, generó el núcleo primordial para la asimilación de un concepto del derecho cultural contemporáneo como parte de los derechos económicos, sociales y culturales (DESC), y, por el otro, sentó las bases para la incorporación de mecanismos de seguimiento de la ejecución de tales derechos que, como - por referir uno- la creación del Comité de Derechos Económicos, Sociales y Culturales (CDESC) por la ONU, en 1985, siguieron un largo proceso en el que se examinaron las respuestas efectivas de los Estados.

El surgimiento de los DESC ofreció, además, un análisis relevante para facilitar que los Estados regularan el derecho a la cultura, ya que en lo tocante a ello se plantearon otras obligaciones estatales que, a decir de Abramovich, Añón y Courtis (2003:59), podrían definirse en cuatro propuestas

[...] obligaciones de respetar, obligaciones de proteger, obligaciones de asegurar y obligaciones de promover el derecho en cuestión. Las obligaciones de respetar se definen el deber del Estado en no injerir, obstaculizar o impedir el acceso al goce de los bienes que constituyen dicho derecho. Las obligaciones de proteger consisten en impedir que terceros interfieran, obstaculicen o impidan el acceso a esos bienes. Las obligaciones de asegurar suponen asegurar que el titular del derecho acceda al bien cuando no puede hacerlo por sí mismo. Las obligaciones de promover se caracterizan por el deber de desarrollar condiciones para que los titulares del derecho accedan al bien.

Como se advierte, cada obligación involucra la doble postura de abstención y de responsabilidad que he identificado en referencia a la situación del Estado en el cumplimiento del derecho. Este avance fue fundamental, puesto que clarificó la actividad del Estado en su relación con la cultura, lo que, a su vez, dio la posibilidad de evaluar las posturas tomadas en el cumplimiento de tal derecho.

Es de interés señalar que los anteriores instrumentos jurídicos forman, de hecho, los RIDH, ${ }^{4}$ que dotan de elementos y criterios suficientes para desarrollar un concepto del derecho cultural, que comprende:

a) El desarrollo libre de la actividad cultural (libertad ante el Estado), y

b) La protección de los elementos que promuevan y generen una vida cultural (obligación del Estado). ${ }^{5}$

\footnotetext{
${ }^{4}$ Regímenes Internacionales de los Derechos Humanos.

${ }^{5}$ En este REPORTE se consideran cuatro niveles de obligaciones. Pode-
}

Estos dos incisos, como digo, brindan una dupla de principios que conceptualiza el derecho cultural como un conjunto de normas jurídicas que, por una parte, posibilita, además del desarrollo libre de la actividad cultural, la protección de los elementos que promueven la generación y la participación de la cultura, y, por la otra, enmarca la acción del concepto, al hacer visible que la protección de la cultura recae en el Estado y deriva de los $\mathrm{RIDH}$, de los cuales particularmente el PIDESC promovió criterios para la determinación de las obligaciones implicadas en el derecho de la cultura.

Adicionalmente, se explicitan los avances que la agenda de derechos humanos proporcionó al sector cultural. En primer lugar, a pesar de las constituciones nacionales que ya preveían la cultura en sus sistemas jurídicos, la DUDH (ONU 1948) y la DADDH ${ }^{6}$ (OEA 1948) promovieron y adoptaron la cultura como un tema social de interés global, iniciando un progreso que logró consolidar criterios y pautas que influyeran en el comportamiento de los diversos actores internacionales. Los criterios seleccionados se fundamentaron en mejor medida con el PIDESC, como ya he descrito arriba, en beneficio de la vida cultural.

\section{Catalogación del derecho cultural}

Como mostré en el apartado anterior, ha sido por medio de los regímenes internacionales como las OIG han influido mayormente en la política de derechos culturales del mundo. Su presencia, de hecho, ha propiciado la aceptación de nuevos temas que la agenda internacional no había adoptado debido a su tradición política. Fue entonces gracias a la entrada de las OIG como los temas de medio ambiente y derechos humanos, al igual que diversos aspectos sociales, entre los que se encuentra el derecho cultural, adquirieron una gran relevancia. ${ }^{7}$

El surgimiento de los RIDH como un marco de acción también ha influido en la creación de conceptos y formas de aproximarse al tema de la cultura. Como manifestación de ello, véase la preparación de una catalogación del derecho cultural; Halina Niec (2001:288), quien presentó en "Los derechos humanos en perspectiva" una propuesta para catalogarlo basada en una división sobre el derecho a la vida cultural, promovida por el Consejo de Europa $(1949)^{8}$ a seguir:

mos ubicar, por un lado, en el inciso a, la obligación de respetar; en el b, las obligaciones de proteger, asegurar y promover.

${ }^{6}$ La ya citada Declaración Americana de los Derechos y Deberes del Hombre.

${ }^{7}$ A partir del paradigma transnacional, se considera la distinción entre dos tipos de políticas: por un lado, las high politics, que hacen especial hincapié en aspectos de seguridad mundial y, por el otro, las low politics, que abarcan temas económicos y sociales (Elias y Sutch 2007:73).

${ }^{8}$ El Consejo de Europa fue creado en 1949, con sede en Estrasburgo, que surge como parte del régimen europeo encargado de salvaguardar 
El derecho a escoger una o varias culturas y de pertenecer a ellas y la libertad de expresarlas, el derecho de acceso a la cultura; el derecho a gozar de los beneficios de la cultura, incluida la protección de tales beneficios; el derecho a contribuir en el desarrollo cultural; el derecho a la igualdad de oportunidades y a la no discriminación, a fin de promover la democracia cultural; el derecho de acceso a los medios de difusión; el derecho a la cooperación cultural internacional; el derecho al acceso de información.

Asimismo, Niec (2001:291) planteó observar la lista de derechos culturales que impulsó el Instituto de Estudios Interdisciplinarios sobre Ética y Derechos Humanos de la Universidad de Friburgo, Suiza, en el proyecto preliminar del protocolo a la Convención Europea para la Protección de los Derechos Humanos y las Libertades Fundamentales, ${ }^{9}$ la cual incluye una categorización interesante, a saber:

Toda persona tiene a título individual, y comparte con otros, el derecho al respeto y a la expresión de sus valores y tradiciones culturales en la medida en que no sean contrarios a las exigencias de la dignidad humana, los derechos humanos y las libertades fundamentales; ese derecho abarca:

a) la libertad de realizar una actividad cultural, en público o privado, y más especialmente hablar el idioma que elija;

b) el derecho a identificarse con las comunidades culturales que elija y a mantener relaciones con ellas; esto implica la libertad de modificar tal elección o de no identificarse con ninguna comunidad cultural;

c) el derecho a que no se le impida descubrir la variedad completa de culturas que conjuntamente constituyen el patrimonio común de la humanidad;

d) el derecho al conocimiento de los derechos humanos y a tomar parte en el establecimiento de una cultura regida por los derechos humanos (Cahmin 1993:3-4).

Cabe aquí señalar los importantes esfuerzos tanto del Consejo de Cooperación Cultural (CDCC) como del Comité $A d-H o c$ para la Protección de las Minorías Nacionales (Cahmin), del propio Consejo de Europa, para determinar una clasificación del derecho cultural: en efecto, estos dos proyectos preliminares presentan un panorama amplio de ámbitos culturales que trasciende los meros derechos a la adopción de una lengua y la identidad cultural.

Las categorizaciones anteriores evidencian que la catalogación del derecho cultural ni ha sido empresa fácil ni ha atraído los consensos necesarios. A manera de propuesta, planteo que el estudio de los diversos instrumen-

los derechos humanos y libertades fundamentales; asimismo, para buscar su mayor efectividad.

${ }^{9}$ El Comité Ad-Hoc para la Protección de las Minorías Nacionales le daría forma posteriormente a este proyecto. tos internacionales nos aproxima a una realidad viable y congruente para la cultura universal. Particularmente, sugiero remitirse a la Declaración de Friburgo sobre Derechos Culturales (DFDC) (UNESCO 2007), que dispone de una clasificación que permite, al aglutinar todos aquellos derechos culturales dispersos en la totalidad de los RIDH, el estudio práctico y conciso del derecho cultural. Cito de la mencionada declaración de derechos culturales dos argumentos de refuerzo: ${ }^{10}$

(8) Considerando que una clarificación del lugar que ocupan los derechos culturales en el seno del sistema de los derechos humanos, junto con una mejor comprensión de su naturaleza y de las consecuencias de sus violaciones, son el mejor medio de evitar que sean utilizados a favor del relativismo cultural, o como pretexto para enfrentar comunidades o pueblos;

(9) Estimando que los derechos culturales enunciados en la presente Declaración están actualmente reconocidos de manera dispersa en un gran número de instrumentos de derechos humanos, y que es importante reunirlos para garantizar su visibilidad y coherencia, y para favorecer su eficacia (UNESCO 2007:1).

Como se aprecia, el aporte de la DFDC (UNESCO 2007) es por demás fundamental, ya que los RIDH presentaban hasta antes de ésta un vasto complejo de criterios, normas y principios culturales que la declaración asimila en una agrupación formal, lo que deviene en claridad y distinción jurídicas. De ello se deriva la clasificación que se muestra en la Figura 1.

Así, la DFDC (UNESCO 2007) incluye seis derechos culturales, cuyo análisis debe emprenderse, con su complejidad, de forma separada.

Baste aquí visualizar el logro de los instrumentos internacionales mencionados, puesto que en conjunto mejoraron la normatividad que rige la práctica de diversas manifestaciones de la vida cultural, no sólo al clasificarla sino también mediante la reincorporación de nociones jurídicas que modificaron el esquema conceptual del derecho cultural. Particularmente, la DFDC (UNESCO 2007) es un ejemplo de cómo los RIDH influyen de manera positiva en la construcción de principios y definiciones de un área específica —en nuestro caso, el derecho cultural—, con lo que se alienta su estudio, aceptación y acercamiento con la sociedad. Este tipo de tratamiento, además de facilitar la aceptación y la aplicación de un tema tan vasto, favorece su interacción con los medios de comunicación de los académicos, las organizaciones civiles, de diversas instituciones, así como con gobiernos y la sociedad, y expande un conocimiento más amplio y fácil de utilizar.

Una vez analizada la catalogación formada y promovida por los derechos humanos, es momento de tratar el derecho cultural en sus diversas expresiones. El caso que

\footnotetext{
${ }^{10}$ Las cursivas son mías.
} 


\begin{tabular}{|l|l|}
\hline \multicolumn{1}{|c|}{ Considerandos } & Oportunidad \\
\hline 1 Principios fundamentales & $\begin{array}{c}\text { Principios y } \\
\text { definiciones }\end{array}$ \\
\hline $\begin{array}{l}\text { Definiciones } \\
4 \text { Referencias a comunidades culturales }\end{array}$ & $\begin{array}{c}\text { Derechos } \\
\text { culturales }\end{array}$ \\
\hline $\begin{array}{l}\text { Acceso y participación en la vida } \\
\text { cultural }\end{array}$ & \\
7 Información y comunicación & \\
8 Cooperación cultural & \\
\hline $\begin{array}{l}11 \text { Responsabilidad de los actores públicos } \\
12 \text { Responsabilidad de las Organizaciones } \\
\text { Internacionales }\end{array}$ & \\
\hline
\end{tabular}

Declaración de Friburgo sobre los Derechos Culturales (DFDC 2007 : 2)

FIGURA 1. Derechos Culturales en la Declaración de Friburgo (Fuente: Declaración de Friburgo, UNESCO 2007).

me ocupará aquí será, entonces, el derecho del patrimonio cultural, que abordaré desde el punto de vista de su formación y consolidación, y en particular, de su asimilación en México.

\section{Formación y consolidación del derecho del patrimonio cultural}

El derecho del patrimonio cultural ha tenido un proceso de formación y consolidación basado en los $\mathrm{RIDH}^{11}{ }^{11}$ que, como se ha visto, han logrado influencia directa, al generar un sistema conceptual plasmado en acuerdos que, a su vez, imponen las obligaciones a los Estados respecto de la cultura y sus nociones correspondientes. Los momentos decisivos de dicho proceso de formación se estudian a continuación, en particular los principios referidos a la noción de patrimonio cultural.

En cuanto al desarrollo de este concepto, conviene citar la Convención de La Haya (UNESCO 1954), que estableció la noción universal del bien cultural y sus posibles formas de resguardo, lo que se decanta en el primer párrafo del artículo 1:

\footnotetext{
${ }^{11}$ Regímenes Internacionales de los Derechos Humanos.
}

[...] se considerarán bienes culturales, cualquiera que sea su origen y propietario: los bienes, muebles o inmuebles, que tengan una gran importancia para el patrimonio cultural de los pueblos, tales como los monumentos de arquitectura, de arte o de historia, religiosos o seculares, los campos arqueológicos, los grupos de construcciones que por su conjunto ofrezcan un gran interés histórico, artístico o arqueológico, así como las colecciones científicas y las colecciones importantes de libros, de archivos o de reproducciones de los bienes antes definidos (UNESCO 1954:art. 1).

La noción de patrimonio cultural no apareció definitivamente sino hasta 1972, con la Convención para la Protección del Patrimonio Mundial Cultural y Natural (CPPMCN) (UNESCO 1972), que lo define como:

A los efectos de la presente Convención se considerará pa-
trimonio cultural:
- Los monumentos: obras arquitectónicas, de escultura o de
pintura monumental, elementos o estructuras de carácter
arqueológico, inscripciones, cavernas y grupos de elemen-
tos, que tengan un valor universal excepcional desde el
punto de vista de la historia, del arte o de la ciencia.
- Los conjuntos: grupos de construcciones, aisladas o reu-
nidas, cuya arquitectura, unidad e integración en el paisa-
je les dé un valor universal excepcional desde el punto de
vista de la historia, del arte o de la ciencia.
- Los lugares: obras del hombre u obras conjuntas del hom-
bre y la naturaleza así como las zonas, incluidos los lugares
arqueológicos que tengan un valor universal excepcional
desde el punto de vista histórico, estético, etnológico o an-
tropológico (UNESCO 1972:art. 1).

Como se aprecia, ambas convenciones conciben el patrimonio cultural en función de su valor universal, y, al señalar el mérito que tienen todos aquellos bienes para la humanidad, lo convierten implícitamente en un tema primordial en la agenda global. Asimismo, a lo largo de su articulado, estas normativas internacionales, a la par que plasman la importancia del patrimonio cultural para todos los pueblos del mundo, determinan que cada Estado firmante debe seleccionar, con base en valores particulares de la nación, los bienes patrimoniales que han de quedar bajo competencia de su normatividad interna de protección, salvaguardia y conservación.

Una definición de carácter más envolvente y antropológico deviene de la Declaración de México sobre las Políticas Culturales (DMPC) de 1982 (UNESCO 1982), la cual establece que el patrimonio cultural de un pueblo

Comprende las obras de sus artistas, arquitectos, músicos, escritores y sabios, así como las creaciones anónimas, surgidas del alma popular, y el conjunto de valores que dan sentido a la vida: es decir, las obras materiales y no materiales que expresan la creatividad de ese pueblo: la lengua, 
los ritos, las creencias, los lugares y monumentos históricos, la literatura, las obras de arte y los archivos y bibliotecas (UNESCO 1982:art. 23).

Es de notar que de esta declaración surge la justificación universal de la existencia del patrimonio cultural, ya que éste — categóricamente señala - dota y da sentido a la vida por medio de la expresión de diversas visiones del mundo plasmadas en obras y creaciones, capaces de elevar al ser humano a su punto más trascendental de existencia. Así, en la normativa internacional el patrimonio cultural ha adquirido una razón de ser que, en tanto invita a la colaboración no sólo en términos de la responsabilidad de una nación en particular sino de todo el mundo, comporta un fuerte argumento de corresponsabilidad. Concomitantemente, el patrimonio cultural se concibe como un bien que no debe ser inaccesible, sino todo lo contrario: promoverse en su disfrute y su cuidado, de donde se desprende la necesidad de una normatividad que ha de regular tanto su acceso - en el catálogo de los derechos culturales de la DFDC, enunciado como el derecho a acceder a los patrimonios culturales - como su uso. El párrafo e del artículo 3 de la DFDC dice:

Toda persona, individual o colectivamente, tiene derecho: [...]

e) A acceder, en particular a través del ejercicio de los derechos a la educación y a la información, a los patrimonios culturales que constituyen expresiones de las diferentes culturas, así como recursos para las generaciones presentes y futuras (UNESCO 2007:6).

Así, en el amplio espectro de la actividad cultural, acrecentado por la globalización, el patrimonio cultural aparece como un modelo o referencia, como un sólido elemento que enriquece tangiblemente la vida cultural de todos los niveles sociales y cuenta con un bien congruentemente delimitado, viable generador de historia y educativo; al referirlo, se habla de manifestaciones humanas capaces de dirigir el rumbo de la cultura de una nación.

De vuelta a la noción de patrimonio cultural, también vale la pena considerar la propuesta que, estrechamente ligada a las justificaciones de los RIDH, ha planteado Josué Llull Peñalba (2005:181): lo define como el

Conjunto de manifestaciones $\mathrm{u}$ objetos nacidos de la producción humana, que una sociedad ha recibido como herencia histórica, y que constituyen elementos significativos de su identidad como pueblo. Tales manifestaciones u objetos constituyen testimonios importantes del progreso de la civilización y ejercen una función modélica o referencial para toda la sociedad, de ahí su consideración como bienes culturales. El valor que se les atribuye va más allá de su antigüedad o su estética, puesto que se consideran bienes culturales los que son de carácter histórico y artístico, pero también los de carácter archivístico, documental, bibliográfico, material y etnográfico junto con las creaciones y aportaciones del momento presente y el denominado legado inmaterial (Llull 2005:181).

Esta aproximación, aunada a las observaciones derivadas de los RIDH arriba planteados, efectivamente subraya el carácter interdisciplinario del patrimonio cultural, que prevé: a) el tipo de manifestaciones culturales consideradas para el conocimiento y la conservación; $b$ ) los criterios histórico-artísticos adoptados para determinar el valor de los objetos patrimoniales; c) el origen de las leyes enfocadas en garantizar la conservación de estos bienes, y d) la intencionalidad educativa en los procesos de enseñanza-aprendizaje que ha orientado tanto el conocimiento como la valoración de los bienes culturales (Llull 2005:182) (Figura 2).
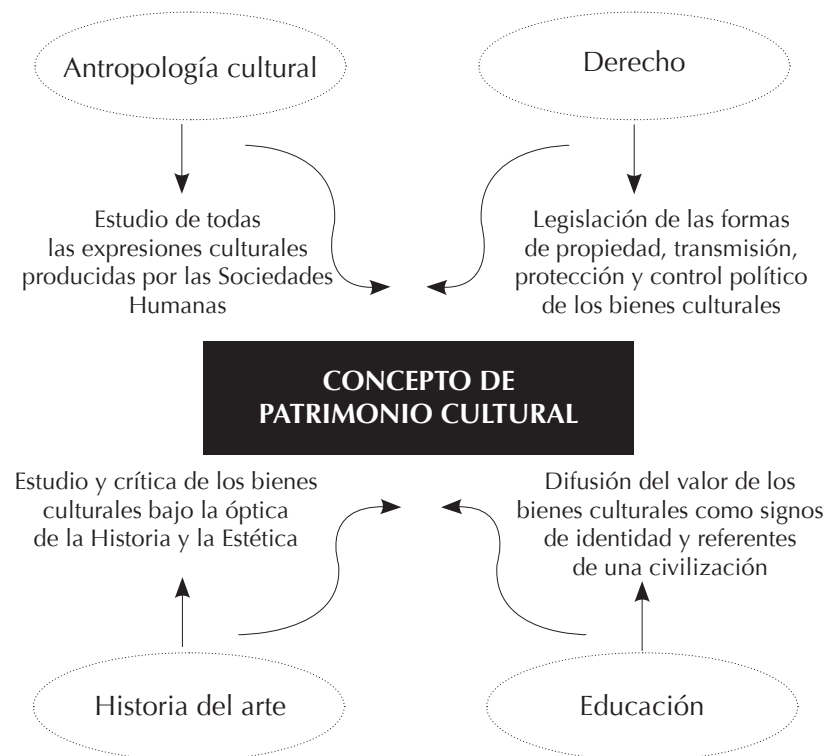

FIGURA 3. Derecho Patrimonial Cultural Mexicano (Crítica a la normatividad vigente) (Fuente: Jaime Allier Campuzano 2006:11-12).

El análisis que hasta ahora he presentado deriva de emplear la teoría de los regímenes internacionales como herramienta de prospección e indagación conceptual. En el marco de la disciplina de las relaciones internacionales, esta visión transnacional puede complementarse si integra el origen de las leyes que, justamente, están dirigidas a garantizar la conservación de dicho patrimonio.

En este sentido, hay que remarcar que la existencia del derecho del patrimonio cultural debe contenerse, en palabras de Fernández Liesa, en

[...] un objeto debidamente identificado, normas dedicadas a dar una regulación específica a ese objeto, una producción doctrinal que trata de señalar con rigor los fundamentos dogmáticos de esta regulación y [...] los institutos correspondientes que regulen dicho objeto (Fernández 2012:135). 
Sugiero entonces, en consideración de los acuerdos internacionales de derechos humanos antes abordados, la siguiente definición del derecho del patrimonio cultural: rama del derecho cultural encargada de regular: a) la protección (obligación del Estado) de los bienes culturales, y b) el acceso (libertad ante el Estado) ${ }^{12}$ a los bienes que los pueblos libremente consideran de valor excepcional. Propongo, asimismo, que la protección de los bienes culturales - los cuales pueden constituir núcleos de la regulación internacional de derechos humanos-conlleva un esquema normativo internacional que, conjuntamente con las políticas culturales, beneficia el desarrollo cultural integrado de un país.

Mi definición — cabe señalarlo en este momento- responde al esquema positivo de los DESC, ${ }^{13}$ que ponen el énfasis en dos rubros: en el objeto de resguardar estos bienes -que incluso pueden ser las producciones, las creaciones de individuos, lo concerniente a la propiedad intelectual y todas aquellas obras que el Estado considere-, por un lado, y en la responsabilidad primordial del Estado de respetar la libertad inherente de los ciudadanos de participar en la vida cultural de la sociedad, por el otro. Asimismo, esta concepción que planteo asume que cada Estado en lo particular definirá tanto las características, virtudes y valores de sus bienes culturales, para considerarlos en su legislación vigente, como las medidas de acceso a éstos y su disfrute.

\section{Consideraciones finales: hacia un derecho al patrimonio cultural en México}

Ciertamente, las medidas que un país adopte para resguardar el derecho del patrimonio cultural han de estipularse, tanto en su constitución política, como en la adopción de normas internacionales que fortalezcan la implementación y promoción de las mismas, para después fortalecer las instituciones u órganos que tengan como encomienda establecer las medidas adecuadas para dicho resguardo, esto debido a la responsabilidad internacional de un Estado ya que para Modesto Seara Vásquez "Ios hechos de un Estado comprenden el comportamiento de todos sus órganos, sean del gobierno central o de una entidad federativa, el legislativo puede cometer transgresiones al promulgar leyes contrarias al derecho internacional o por no promulgar leyes necesarias para cumplir las obligaciones internacionales"(Castañeda 2012:221). La influencia doctrinal y normativa de los RIDH es también notable en el abordaje de la noción del derecho del patrimonio cultural en México, tanto en la propia elaboración de un concepto de patrimonio cultural como de una catalogación de los derechos culturales que directa o indirectamente condiciona

\footnotetext{
${ }^{12}$ De igual manera se insertan los cuatro niveles de análisis de las obligaciones expuestas anteriormente; para el inciso a, proteger, asegurar y promover; para el b, la de respetar.

${ }^{13}$ Derechos económicos, sociales y culturales, le recuerdo al lector.
}

las formas de interpretar diversos temas específicos. Ejemplo de ello puede encontrarse en el catálogo del derecho cultural propuesto por el doctor Ávila Ortiz (2000:62-63), el cual comulga con un planteamiento similar de los documentos internacionales antes citados, a seguir:

1. Derecho cultural general: disposiciones constitucionales referidas a la cultura; derecho de la educación; derecho universitario; derecho de autor; derecho del patrimonio cultural; derecho de las artes; derecho de los medios de comunicación.

2. Derecho cultural de las comunidades nacionales: derecho de las comunidades indígenas; derecho de la promoción de las culturas populares; derecho de los símbolos nacionales.

3. Derecho cultural internacional: derecho de la cooperación y el intercambio cultural internacional; derecho del Estado nacional en materia cultural.

Esta aproximación académica es de gran valor para nuestro ámbito cultural nacional no sólo por razón de que se apega a la doctrina internacional mencionada arriba sino porque los derechos culturales que comprende están, en su mayoría, concebidos por los RIDH. Ahora bien, un aspecto en el que vale insistir es que, como se constata, el derecho del patrimonio cultural aparece como parte del derecho cultural en general.

Alternativamente, Allier Campuzano hace una proposición importante respecto de la clasificación del patrimonio cultural (Figura 3): sugiere apegarse a la normatividad vigente de México, utilizando para ello el concepto de patrimonio monumental que José Becerril Miró (2003:9-10) define como

[...] el conjunto de bienes producto de culturas pretéritas, producto de la acción conjunta o separada de hombre y la naturaleza, que tienen una relevancia histórica, estética, arquitectónica, urbanística, económica, social, política, tradicional, etnológica, antropológica, científica, tecnológica, e intelectual para un pueblo.

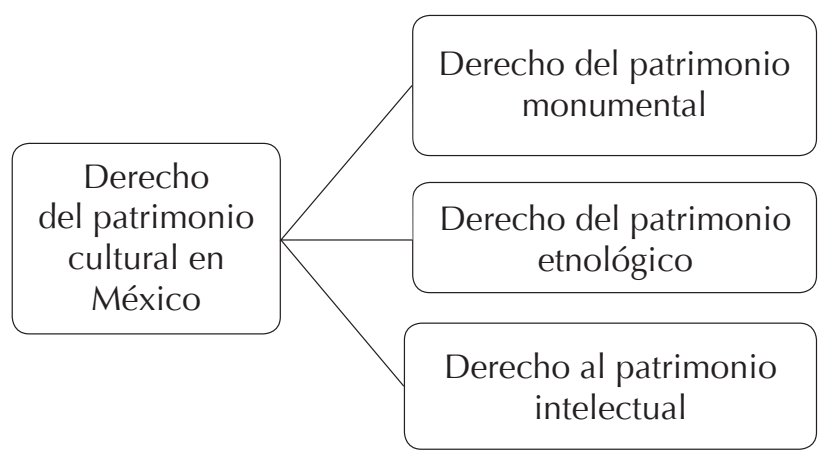

FIGURA 2. Evolución del concepto y de la significación social del patrimonio cultural (Fuente: Josué Llull Peñalba 2005:181). 
Como afirma Allier Campuzano (2006:11), este último engarce jurídico tiene amplias potencialidades de conciliación, ya que la normatividad vigente en México a la que habría que apegarse sería la Ley Federal sobre Monumentos y Zonas Arqueológicos, Artísticos e Históricos (LFMZAAH) (CUEUM 1972), el aparato legal normativo de mayor potencia en materia de protección, investigación y conservación del patrimonio cultural de nuestro país.

En el marco de estas ideas, mi definición de derecho del patrimonio cultural ratifica la noción de que el Estado tiene la obligación de respetar, proteger, asegurar y promover el cuidado y el acceso a los bienes culturales del pueblo de México, la cual ya estaría normada por la LFMZAAH (CUEUM 1972), aunque corresponde verificar y constatar con mucho mayor detalle lo que determina el ejercicio de esta ley, en especial en cuanto a las tareas de registro, las sanciones de maltrato a los bienes y la clasificación del patrimonio, o categorías patrimoniales. De hecho, se observa que estas obligaciones están integradas en la Ley Orgánica del Instituto Nacional de Antropología e Historia (INAH, México), que cifra como uno de sus objetivos

[...] la investigación científica sobre Antropología e Historia relacionada principalmente con la población del país y con la conservación y restauración del patrimonio cultural arqueológico e histórico, así como el paleontológico; la protección, conservación, restauración y recuperación de ese patrimonio y la promoción y difusión de las materias y actividades que son de la competencia del Instituto (INAH 1939:art. 2).

Sin mayor escrutinio, queda claro que tanto el Estado mexicano ha tratado mediante estas dos legislaciones de cumplir con las cuatro obligaciones respecto del patrimonio cultural como que es necesario generar análisis que coadyuven a su evolución. Una primera propuesta originada del presente estudio consiste en analizar como vía de perfeccionamiento dichas leyes utilizando como herramienta los RIDH. Enseguida se plantea no sólo fortalecer la observancia de estos cuerpos legales a la luz de su relevancia en México sino corregir sus deficiencias de acuerdo con los esquemas contemporáneos de los cuatro niveles de obligación surgidos del PIDESC. ${ }^{14}$ Este proceso no sólo es arquetípico sino necesario para un país en el que la cultura está perdiendo dirección o carece de un concepto delimitado con precisión. El derecho del patrimonio cultural en México puede marcar las directrices en el establecimiento de políticas que beneficien a la cultura nacional. En esta idea, el patrimonio cultural juega una función modélica o direccional con un fuerte respaldo normativo, como se aprecia en la Figura 4.

\footnotetext{
${ }^{14}$ El Pacto Internacional de Derechos Económicos, Sociales y Culturales.
}

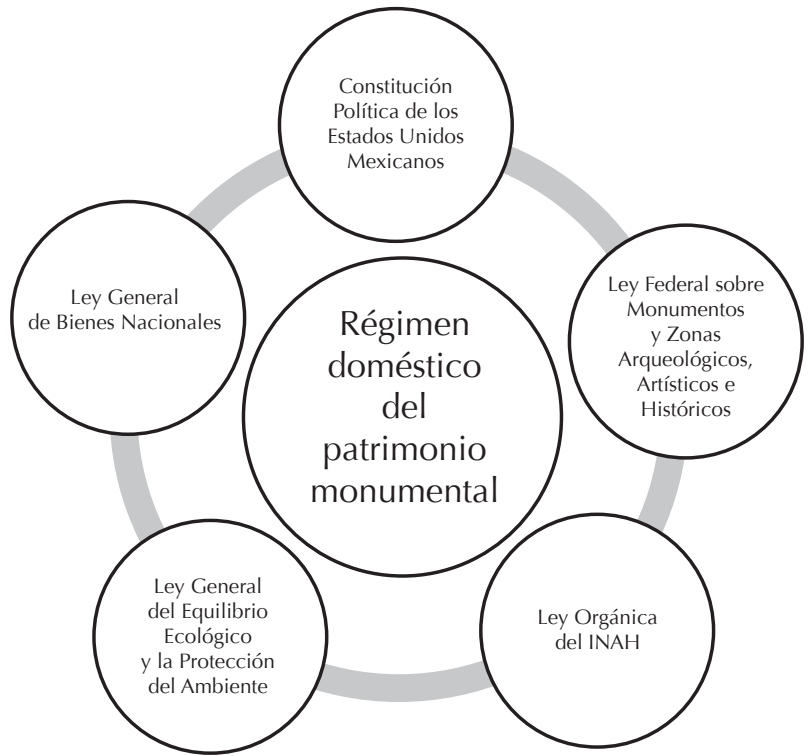

FIGURA 4. Régimen doméstico del patrimonio monumental en México (Esquema: Miguel Ángel Mesinas Nicolás).

Para concluir, menciono que este REPORTE, lejos de proponer un análisis acabado que establezca un ideal conseguido, señala que la trayectoria mundial del derecho del patrimonio cultural será gradual. No obstante que no es fácil de alcanzar su empresa, en México, gracias a su legislación y a la formación de instituciones como el INAH, se ha iniciado el camino. Espero que su desarrollo continúe apoyado no sólo desde el cuerpo de las relaciones internacionales sino también desde el paisaje interdisciplinario, el cual permitirá enriquecer, consolidar y fomentar el desarrollo de esta normatividad, en aras de abarcar al máximo aquellas necesidades culturales de una sociedad que permiten que el ser humano viva en plena libertad.

\section{Referencias}

Abramovich, Víctor, María José Añón y Christian Courtis 2003 Derechos sociales: instrucciones de uso, México, Fontamara.

Allier Campuzano, Jaime

2006 Derecho patrimonial cultural mexicano (crítica a la normatividad vigente), México, Porrúa.

Anaya Muñoz, Alejandro

2014 Los derechos humanos en y desde las relaciones internacionales, México, CIDE.

Anon.

1932 "Controversia constitucional entre la federación y el estado de Oaxaca, por la expedición de la Ley de Monumentos Arqueológicos", Semanario Judicial, (5) xxxVı:612-615, documento electrónico disponible en [http://biblio.juridicas.unam.mx/libros/2/830/108.pdf], consultado en febrero del 2016. 
Arenal, Celestino del

2010 Introducción a las relaciones internacionales, Madrid, Tecnos.

Ávila Ortiz, Raúl

2000 Derecho cultural en México: una propuesta académica para el proyecto político de la modernidad, México, UNAM/Porrúa.

Becerril Miró, José Ernesto

2003 El derecho del patrimonio histórico-artístico en México, México, Porrúa.

Cahmin

1993 Avant-project de protocole à la Convention européenne de sauvegarde des droits de l'homme et des libertés fondamentales, concernant la reconnaissance des droits culturels, documento electrónico disponible en [https:// www.coe.int/t/dghl/monitoring/minorities/6_resources/ PDF_CAHMIN(94)4rev\%20fr.pdf], consultado en febrero del 2016.

$\mathrm{CC}$

1917 "Artículo 2", Constitución Política de los Estados Unidos Mexicanos, México, Congreso Constituyente de México.

CDESC

2009 "Observación general núm. 21", Derecho de toda persona a participar en la vida cultural, Ginebra, Comité de Derechos Económicos, Sociales y Culturales (CDESC), documento electrónico disponible en [http://conf-dts1. unog.ch/1\%20SPA/Tradutek/Derechos_hum_Base/CESCR/00_1_obs_grales_Cte\%20Dchos\%20Ec\%20Soc\%20 Cult.html\#GEN21], consultado en junio de 2015.

Castañeda, Mireya

2012 El Derecho Internacional de los Derechos Humanos y su recepción nacional, México, CNDH.

CUEUM

1934 "Ley sobre Protección y Conservación de Monumentos Arqueológicos, Históricos, Poblaciones Típicas y Lugares de Belleza Natural", Diario Oficial de la Federación, México, Congreso de la Unión de los Estados Unidos Mexicanos (CUEUM), viernes 19 de enero, documento electrónico disponible en [http://dof.gob.mx/nota_to_imagen_fs.php?cod_diario $=191190 \&$ pagina $=5 \&$ seccion $=0$ ], consultado en abril del 2016.

1972 "Ley Federal sobre Monumentos y Zonas Arqueológicos, Artísticos e Históricos", Diario Oficial de la Federación, México, Congreso de la Unión de los Estados Unidos Mexicanos (CUEUM), sábado 6 de mayo, documento electrónico disponible en [http://www.diputados.gob.mx/LeyesBiblio/pdf/131_280115.pdf], consultado en julio 2015.

Elias, Juanita y Peter Sutch 2007 The Basics. International Relations, Londres, Routledge.

Fernández Liesa, Carlos 2012 Cultura y derecho internacional, Madrid, Solana e Hijos.

García Picazo, Paloma

2009 Teoría breve de las relaciones internacionales, Madrid, Tecnos.
González Oropeza, Manuel

1998 Las controversias entre la Constitución y la política, México, UNAM.

INAH

1939 “Ley Orgánica del Instituto Nacional de Antropología e Historia (LOINAH), México", Instituto Nacional de Antropología e Historia (INAH) [página web], documento electrónico disponible en [http://www.gobiernodigital.inah.gob. $\mathrm{mx} /$ Transparencia/Archivos/loinah.pdf],consultado en febrero del 2016.

Llull Peñalba, Josué

2005 "Evolución del concepto y de la significación social del patrimonio cultural", Arte, Individuo y Sociedad, 17:177-204.

Niec, Halina

2001 "Sentar las bases para la realización de los derechos culturales", en H. Niec (ed.), ¿A favor o en contra de los derechos culturales? Compilación de ensayos en conmemoración del cincuentenario de la Declaración Universal de los Derechos Humanos, París, UNESCO, 279-298.

OACNUDH

2009 Preguntas frecuentes sobre los Derechos Económicos, Sociales y Culturales, Nueva York, Oficina del Alto Comisionado de Naciones Unidas en Derechos Humanos (OACNUDH) (Folleto Informativo 33), documento electrónico disponible en [http://www.ohchr.org/Documents/Publications/FS33_sp.pdf], consultado en julio del 2015.

OEA

1948 "Declaración Americana de Derechos y Deberes del Hombre, Artículo XIII", Ix Conferencia Internacional Americana, Bogotá, Organización de los Estados Americanos (OEA), documento electrónico disponible en [https://www. oas.org/dil/esp/Declaraci\%C3\%B3n_Americana_de_los_ Derechos_y_Deberes_del_Hombre_1948.pdf], consultado en noviembre del 2015.

ONU

1948 "Artículo 27", Declaración Universal de los Derechos Humanos, Nueva York, Organización de las Naciones Unidas (ONU), documento electrónico disponible en [http:// www.un.org/es/documents/udhr], consultado en noviembre del 2015.

1966a Pacto Internacional de Derechos Económicos, Sociales y Culturales, Nueva York, Organización de las Naciones Unidas (ONU), documento electrónico disponible en [http://www.ohchr.org/SP/ProfessionalInterest/Pages/CESCR.aspx], consultado en noviembre del 2015.

1966b Pacto Internacional de Derechos Civiles y Políticos, Nueva York, Organización de las Naciones Unidas (ONU), documento electrónico disponible en [http://www.ohchr. org/SP/ProfessionalInterest/Pages/CCPR.aspx], consultado en noviembre del 2015.

2015 "Derecho Internacional", Temas mundiales, Organización de las Naciones Unidas (ONU), documento electrónico disponible en [http://www.un.org/es/globalissues/ law/\#text], consultado en noviembre del 2015. 
UNESCO

1954 Convención para la Protección de los Bienes Culturales en caso de Conflicto Armado y Reglamento para [su] Aplicación, París, Organización de las Naciones Unidas para la Educación, la Ciencia y la Cultura (UNESCO), documento electrónico disponible en [http://portal.unesco.org/ es/ev.php-URL_ID=13637\&URL_DO=DO_TOPIC\&URL_ SECTION=201.html], consultado en noviembre del 2015. 1972 Convención para la Protección del Patrimonio Mundial Natural y Cultural, París, Organización de las Naciones Unidas para la Educación, la Ciencia y la Cultura (UNESCO), documento electrónico disponible en [http://portal.unesco.org/es/ev.php-URL_ID=13055\&URL_DO=DO_ TOPIC\&URL_SECTION=201.html], consultado en noviembre del 2015.

1982 Declaración de México sobre las Políticas Culturales, México, Organización de las Naciones Unidas para la Educación, la Ciencia y la Cultura (UNESCO), documento electrónico disponible en [http://portal.unesco.org/culture/ es/ev.php

URL_ID $=12762 \& U R L$ _DO $=$ DO_TOPIC\&URL_SEC TION=201.html], consultado en noviembre del 2015.

2007 Declaración de Friburgo sobre Derechos Culturales, Friburgo, Organización de las Naciones Unidas para la Educación, la Ciencia y la Cultura (UNESCO), documento electrónico disponible en [http://www.culturalrights.net/es/ documentos.php?c=14\&p=161], consultado en noviembre del 2015.

\section{Síntesis curricular del/los autor/es}

\section{Miguel Ángel Mesinas Nicolás}

Museo de las Culturas de Oaxaca (MCO),

Instituto Nacional de Antropología e Historia (INAH), México

migue_mesinas@hotmail.com

Licenciado en relaciones internacionales (Universidad José Vasconcelos de Oaxaca [Univas], México). Realizó su servicio social en la sección de antropología social del Centro INAH-Oaxaca del Instituto Nacional de Antropología e Historia (INAH, México). Desde el 2014 está vinculado con el Museo de las Culturas de Oaxaca (MCO-INAH), México, donde actualmente ocupa el cargo de asistente de promotor cultural. Ha participado en diversos talleres relacionados con derechos humanos y culturales, como "Organizaciones no Gubernamentales y Derechos Humanos" (2011); "La geopolítica como herramienta de análisis en el diseño de la política internacional" (2012), y "Modelo de Naciones Unidas" (2012), todos en la Univas; también fue moderador del "Simulacro de Naciones Unidas" (SINUU 2013) en dicha universidad y "Análisis de la Cultura" (2015).

Postulado/Submitted 05.10.15

Aceptado/Accepted 21.04.16

Publicado/Published 11.07.16 